\title{
PENGARUH KELOMPOK REFERENSI DAN BUDAYA TERHADAP KEPUTUSAN MENJADI ANGGOTA SANGGAR TARI
}

Oleh :

Elvira Pradipta Sutiana,

Fakultas Ekonomi Manajemen, Universitas Singaperbangsa Karawang

Email : elvira.pradipta18284@student.unsika.ac.id

Risha Fatikha Sari,

Fakultas Ekonomi Manajemen, Universitas Singaperbangsa Karawang

Email : risha.fatikha18294@student.unsika.ac.id

Ajat Sudrajat

Fakultas Ekonomi Manajemen, Universitas Singaperbangsa Karawang

Email : ajat.sudrajat@fe.unsika.ac.id

\section{Article Info}

Article History :

Received 09 July - 2021

Accepted 02 Sept - 2021

Available Online 25 Sept 2021

Keyword:

Abstract
The consumer behaviour in making purchasing decisions can be
influenced by three factors including internal and external factors
and the decision-making process. The study entitled "The Influence
of Reference Group and Culture on the Decision to Become a
Member of the Dance Studio" aims to analyze the influence of X1
and X2 on Y. By using a quantitative approach and descriptive
analysis, in the variable X1, dimension of value expression
obtained the highest average score with a percentage of $51.82 \%$, in
the X2 variable the highest was the view at $59.50 \%$, in the variable
$Y$ the highest was personality at $25.57 \%$. Whereas in the
verification analysis, the relationship between X1 and X2 is 0.426
which means that the correlation is moderate. For $5 \%$ error the
two-tailed test and $d f=97$ is 1.66071. Because the $t$ statistic $>$ from
$t$ table $(4.328>1.66071), H 0$ is rejected. The significant column
number is $0.000<0.05$. So it means that X1 and X2 partially have a
significant effect on Y.From the ANOVA test or F test, it is found
that the F score is 19.714 with a significant level indicating a value
of $0.000<0.05$, it can be concluded that X1 and X2 are
simultaneously affects Decision $Y$.

Marketing Management,

Reference Group, Culture

\section{PENDAHULUAN}

Kabupaten Karawang merupakan daerah yang memiliki banyak julukan seperti kota Pangkal Perjuangan yang melekat dengan Peristiwa Rengasdengklok, kota Industri karena banyak pabrik yang berdiri dengan ribuan pegawai, juga kota Lumbung Padi yang dahulu terkenal sebagai salah satu kota penghasil padi terbanyak di Indonesia. Karawang juga merupakan daerah yang memiliki bentang alam yang indah, mulai dari gugusan pegunungan sampai bentang pantai yang lumayan panjang. Selain memiliki potensi industri dan alamnya, ternyata Karawang juga memiliki potensi budaya yang sangat kuat dan penuh warna.
Keragaman Kebudayaan Tradisional menjadi salah satu potensi yang dimiliki Kabupaten Karawang.

Kebudayaan tradisional yang dimiliki oleh Kabupaten Karawang sangat beragam. Mulai dari manuskrip, tradisi lisan, adat istiadat, ritus, pengetahuan tradisional, teknologi tradisional, seni, bahasa, permainan rakyat, olahraga tradisional, dan cagar budaya.

Berdasarkan Peraturan Bupati Karawang No 68 Tahun 2018 tentang Badan Musyawarah Masyarakat Karawang Dalam Upaya Pelestarian Kebudayaan Daerah BAB III Pasal 6 bahwa dalam upaya pelestarian kebudayaan daerah diselenggarakan melalui :

a. Pendidikan 
b. Pelatihan

c. Pengembangan bakat dan minat

d. Pembinaan yang berkelanjutan

e. Lomba/festival gebyar budaya

f. Pemeliharaan dan pemantauan

g. Evaluasi dan tindakan

Merujuk pada Pasal 8, bahwa pelestarian daerah sebagaimana dimaksud dalam pasal 6 pada point $\mathrm{b}$ sampai $\mathrm{d}$, diselenggarakan melalui sanggar-sanggar budaya dan diantaranya yaitu sanggar tari, sanggar jaipong, sanggar topeng, sanggar wayang golek dan wayang kulit, dan sanggar ajeng.

Gambar 1 Grafik Jumlah Lembaga menurut Objek Seni

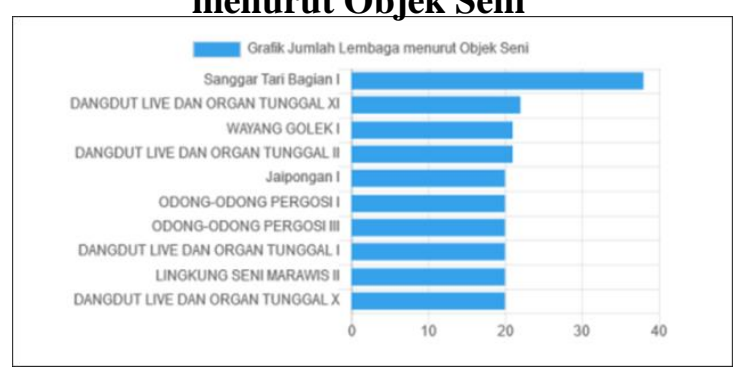

Sumber: PPKD Kab Karawang 2018

Berdasarkan data tersebut yang diambil dari Pokok Pikiran Kebudayaan Daerah (PPKD) Kabupaten Karawang Tahun 2018 yang disediakan oleh PemKab Kabupaten Karawang, sanggar tari merupakan lembaga dengan jumlah terbanyak dibandingkan dengan lembagalembaga seni lainnya.

Banyaknya sanggar tari di Kabupaten Karawang menunjukkan bahwa seni tari masih lumayan banyak diminati di lingkup masyarakat, bahkan dimulai dari anak kecil hingga dewasa. Namun, tidak dapat diketahui apakah alasan masyarakat mengikuti sanggar tari memang karena keinginan dari diri sendiri yang minat dengan seni tari dan ingin melestarikan kebudayaan tradisional atau hanya karena mengikuti ajakan teman maupun paksaan dari orang tua. Perilaku masyarakat sebagai konsumen dalam menentukan keputusan dapat dipengaruhi oleh 3 faktor Swastha dan Handoko (2011:258), yaitu :

a. Faktor-faktor individu atau internal yang menentukan perilaku

b. Faktor-faktor eksternal yang mempengaruhi perilaku konsumen

c. Proses pengambilan keputusan yang dilakukan oleh konsumen

Faktor internal terdiri dari motivasi, persepsi, kepribadian, dan sikap dari individu. Sedangkan faktor eksternal meliputi kebudayaan, sub-budaya, kelas sosial, keluarga, dan juga kelompok referensi. Faktor-faktor tersebut yang akan mempengaruhi konsumen dalam menentukan dan mengambil keputusan. Pada prinsipnya memilih salah satu alternatif dari banyaknya alternatif merupakan suatu proses pengambilan keputusan menurut Sciffman dan Kanuk (2013:437).

Berdasarkan penjelasan yang telah diuraikan di atas, melihat bahwa banyaknya faktor yang bisa mempengaruhi perilaku seorang konsumen dalam mengambil keputusan untuk menjadi anggota sanggar tari. Penulis tertarik untuk membuat penelitian mengenai "Pengaruh Kelompok Referensi dan Budaya terhadap Keputusan Menjadi Anggota Sanggar Tari (Survei pada Anggota Sanggar Tari di 8 Sanggar Tari Kabupaten Karawang)".

\section{KAJIAN PUSTAKA PEGEMBANGAN HIPOTESIS}

DAN

\section{Manajemen Pemasaran}

Kotler dan Amstrong (2012:6) berpendapat bahwa segala proses sosial dan manajerial yang dialami oleh individu maupun kelompok, pribadi maupun organisasi dalam memperoleh semua yang dibutuhkan dan diinginkannya melalui penciptaan dan pertukaran nilai disebut dengan pemasaran. Berikut merupakan gambaran besar manajemen pemasaran :

1. Konsep Pemasaran Jasa

Adapun menurut (Kotler dalam Henry G. Piri, 2013) desain program pemasaran sangat dipengaruhi oleh beberapa karakteristik, yaitu tidak berwujud, tidak terpisahkan dan bervariasi.

2. Bauran Pemasaran Jasa

Kotler dan Amstrong (2012:62) mengatakan bahwa elemen bauran pemasaran jasa ada 7 yaitu Product, Price, Place, Promotion, People, Physical Evidence, dan Process.

\section{Konsep Kelompok Referensi}

Secara nyata suatu individu dapat dipengaruhi oleh orang lain, baik oleh individu juga maupun oleh sekelompok orang yang tergabung dari dua orang atau lebih. Menurut Sumarwan (2011:305) individu atau sekelompok orang yang dapat mempengaruhi itu disebut dengan kelompok referensi. Menurut Peter dan Olson (2013) pada kelompok referensi melibatkan satu orang atau lebih (kelompok) yang dipergunakan sebagai alasan untuk pembandingan atau dijadikan sebagai acuan dalam membentuk respons afektif juga respons kognitif seorang individu serta melakukan 
perilaku.

Penyataan bahwa ada 3 (tiga) indikator yang dimiliki oleh kelompok referensi, yaitu:

1. Pengaruh Normatif

2. Pengaruh Ekspresi Nilai

3. Pengaruh Informasi

\section{Konsep Budaya}

Menurut Hawkins (2012) budaya merupakan sesuatu yang kompleks dimana di dalamnya meliputi suatu keyakinan, pengetahuan, seni, moral, adat-istiadat, serta kemampuan dan kebiasaan lainnya yang dimiliki oleh manusia sebagai suatu bagian dari kelompoknya. Suatu kepercayaan, nilai-nilai, dan kebiasaan yang dipelajari oleh manusia dan dapat mengarahkan manusia tersebut dalam penggunaan suatu produk (barang dan jasa) merupakan definisi dari budaya. Tiga hal yang disebutkan sebelumnya, dapat muncul apabila dalam berperilaku, seseorang itu bisa melakukan interaksi, hubungan, juga bisa saling mempengaruhi satu sama lainnya.

Budaya memiliki beberapa indikator penentu yaitu :

1. Kepercayaan/Keyakinan

2. Pandangan

3. Kebiasaan

\section{A. Konsep Keputusan Pembelian/ \\ Penggunaan Jasa}

Apabila keputusan dalam pembelian yang akan diambil semakin kompleks, biasanya semakin banyak pula hal yang harus dipertimbangkan dalam membeli sebuah barang atau menggunakan jasa. Menurut Kotler dan Amstrong (2012:191) jenis-jenis tingkah laku konsumen dalam membeli barang maupun menggunakan jasa, berdasar pada derajat ketersangkutan juga tingkat perbedaan antar merek dalam melakukan sebuah keputusan untuk pembelian barang atau penggunaan jasa, yaitu :

1. Tingkah laku membeli yang kompleks

2. Tingkah laku membeli yang mnegurangi ketidakcocokan

3. Tingkah laku membeli yang mencari variasi

4. Tingkah laku membeli yang mnejadi kebiasaan

Selain itu proses keputusan membeli / menggunakan jasa menurut Kotler (2016:173) untuk mencapai suatu keputusan pembelian produk atau penggunaan jasa, ada lima tahap yang harus dilalui oleh pembeli, yaitu :

1. Mengenali Kebutuhan

2. Pencarian Informasi
3. Evaluasi Alternatif

4. Keputusan Membeli

5. Tingkah Laku pasca Pembelian

Gambar 2 Proses Keputusan Membeli

\begin{tabular}{l}
$\begin{array}{l}\text { Mengenali } \\
\text { kebutuhan }\end{array} \rightarrow \begin{array}{l}\text { Pencarian } \\
\text { Informasi }\end{array} \rightarrow \begin{array}{l}\text { Evaluasi } \\
\text { Altematif }\end{array} \rightarrow \begin{array}{l}\text { Keputusan } \\
\text { Membeli }\end{array} \rightarrow \begin{array}{l}\text { Tingkah Laku } \\
\text { Pasca Pembelian }\end{array}$ \\
\hline
\end{tabular}

Sumber : Buku pemasaran Jasa (Strategi Mengukur Kepuasan dan Loyalitas

Pelanggan)oleh Dr. Didin Fatihudin, SE., M.Si. dan Dr. M. Anang Firmansyah, SE., MM., 2018

\section{Kerangka Pemikiran}

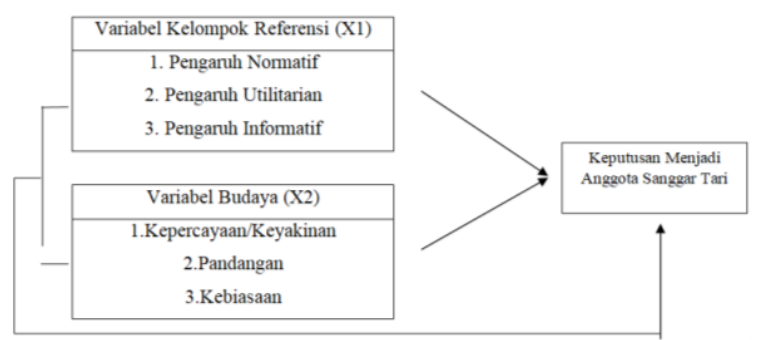

\section{Hipotesis}

1. Terdapat hubungan positif dan signifikan antara variabel kelompok referensi dengan variabel budaya.

2. Terdapat pengaruh positif dan signifikan antara variabel kelompok referensi dan variabel budaya secara parsial terhadap variabel keputusan menjadi anggota sanggar tari.

3. Terdapat pengaruh positif dan signifikan antara variabel kelompok referensi dan komponen variabel budaya secara bersama-sama atau simultan terhadap keputusan menjadi anggota sanggar tari.

\section{METODE PENELITIAN}

\section{Populasi dan Sample}

Menurut Silaen (2018:87) populasi yaitu keseluruhan berbagai objek ataupun individu yang mempunyai karakteristik atau sifat tertentu yang akan di teliti, menurutnya populasi bisa disebut universum (universe) yang artinya keseluruhan baik benda mati ataupun hidup. Sedangkan Sugiyono (2011:80) mengatakan penarikan kesimpulan yang dilakukan peneliti berdasarkan karakteristik atau kualitas obyek serta subyek di wilayah generalisasi untuk selanjutnya dapat dipelajari disebut populasi. Penelitian kali ini yang dijadikan populasi merupakan anggota sanggar tari di Kabupaten Karawang yaitu sanggota sanggar tari puspawangi (40 orang), sekartaji (40 orang), putri bungsu (14 orang), wastu kencana (20 orang), ringkang gumilang ( 85 orang), cici bayoy 
(40 orang), surya medal (50 orang), dan RSAP

(40 orang) yang jika ditotal jumlahnya yaitu 329 orang.

Tabel 1 Populasi Anggota Sanggar Tari di Kabupaten Karawang

\begin{tabular}{|c|c|c|}
\hline $\begin{array}{c}\text { Nama } \\
\text { Sanggar Tari }\end{array}$ & Alamat & $\begin{array}{c}\text { Jumlah } \\
\text { Anggota }\end{array}$ \\
\hline Puspawangi & $\begin{array}{c}\text { Perum Pemda blok A2 } \\
\text { no.7 Telukjambe } \\
\text { Karawang } 41361\end{array}$ & \pm 40 Orang \\
\hline Sekar Taji & $\begin{array}{l}\text { Jalan HS. Ronggo } \\
\text { Waluyo, Teluk Jambe, } \\
\text { Karawang Barat, } \\
\text { Telukjambe, Kec. } \\
\text { Telukjambe Tim., } \\
\text { Kabupaten Karawang, } \\
\text { Jawa Barat 41361. }\end{array}$ & \pm 40 Orang \\
\hline Putri Bungsu & $\begin{array}{c}\text { Jln.Sukamulya rt/rw } \\
\text { 022/006 dekat SMPN 4, } \\
\text { J1. Industri Anggadita, } \\
\text { Anggadita, Kec. Klari, } \\
\text { Kabupaten Karawang, } \\
\text { Jawa Barat } 41371\end{array}$ & \pm 14 Orang \\
\hline $\begin{array}{l}\text { Wastu } \\
\text { Kencana }\end{array}$ & $\begin{array}{l}\text { J1. Raya Tj. Pura No.16- } \\
\text { 10, Tanjungmekar, Kec. } \\
\text { Karawang Bar., } \\
\text { Kabupaten Karawang, } \\
\text { Jawa Barat } 41316\end{array}$ & \pm 20 Orang \\
\hline $\begin{array}{l}\text { Ringkang } \\
\text { Gumilang }\end{array}$ & $\begin{array}{c}\text { J1.Panatayudha No.9, } \\
\text { Karawang Barat } \\
\text { Gow (Gedung } \\
\text { Organisasi Wanita) } \\
\end{array}$ & \pm 85 Orang \\
\hline Cici Bayoy & $\begin{array}{c}\text { Jl.galur no.126 } \\
\text { cikampek selatan Rt } \\
\text { 002/003 .rmh. Bidan } \\
\text { rosea linda, Cikampek } \\
\text { Sel., Kec. Cikampek, } \\
\text { Kabupaten Karawang, } \\
\text { Jawa Barat } 41373\end{array}$ & \pm 40 Orang \\
\hline Surya Medal & $\begin{array}{c}\text { Cikampek, Karawang, } \\
\text { West Java } 41373\end{array}$ & \pm 50 Orang \\
\hline RSAP & $\begin{array}{c}\text { Cikampek, Kabupaten } \\
\text { Karawang, Jawa Barat } \\
41373\end{array}$ & \pm 40 Orang \\
\hline
\end{tabular}

Sumber: Wawancara Pemilik Sanggar, 2020

Sugiyono (2011:84) mengatakan, bagian populasi yang memiliki karakteristik adalah sampel. Jadi, sampel adalah sebagian kecil dari sebuah populasi. Akan tetapi, menurut Arikunto (2012:104) mengatakan jika populasi tidak bisa meraih 100 orang, ambilah semua sampel. Jadi sampel adalah populasinya. Akan tetapi, apabila subjek besar atau melebihi 100 orang, sampel bisa diambil sekitar $10-15 \%$ atau $15-25 \%$ ataupun lebih. Roscoe mengatakan dalam Sugiyono (2011:90) yaitu 30-500 orang sampel sudah termasuk dalam kategori layak pada penelitian. Namun, penelitian kali ini pengambilan sampel berdasarkan teknik slovin dengan menggunakan taraf kesalahan sebesar $10 \%$ dengan rumus :
Dimana :

$$
n=\frac{N}{1+N e^{2}}
$$

n : Ukuran sampel

$\mathrm{N}$ : Ukuran Populasi

E : Nilai kritis (batas ketelitian) yang di inginkan (persen kelonggaran ketidak telitian karena kesalahan penarikan sampel)

$$
\begin{gathered}
n=\frac{329}{1+329(0,1)^{2}} \\
n=\frac{329}{4,29}
\end{gathered}
$$

$n=76,69$ dibulatkan menjadi 77

Jumlah populasi anggota sanggar tari yang kami teliti yaitu 329 orang, berdasarkan perhitungan dengan menggunakkan rumus Slovin diatas dapat diketahui bahwa sampel yang diperoleh sebanyak 77 sampel dengan taraf kesalahan $10 \%$.

\section{Metode Pengumpulan Data}

Merupakan teknik yang dipergunakan untuk memperoleh berbagai data untuk penelitan. Perolehan data sangat dibutuhkan untuk penelitian demi memperoleh data sejelasjelasnya agar dapat dijadikan bahan untuk diolah. Dalam penelitian kali ini peneliti menggunakan data berdasarkan populasi yang diambil sampelnya untuk selanjutnya diolah melalui teknik sampling. Teknik pengumpulan data yang peneliti lakukan adalah dengan survey/penyebaran kuisioner serta wawancara dimana peneliti menggunakan jenis dan sumber data primer serta sekunder dengan penilaian berdasarkan teknik skala likert.

\section{Teknik Analisis Data}

Sugiyono (2015:224) dalam bukunya mengungkapkan bahwa teknik ini merupakan pencarian serta pemrosesan data yang diperoleh secara sistematis berdasaran hasil nyata dari wawancara, catatan lapangan, dokumentasi melalui pengorganisasian data dalam beberapa kategori, penjabaran data kedalam unit tertentu, membuat suatu sintesa, memasukan kedalam susunan pola lalu memilih data mana yang penting dan akan dijadikan simpulan untuk mempermudah orang lain dalam memahaminya. Penelitian kali ini data yang dianalisis merupakan hasil survei dari penelitian lapangan yang merupakan penyebaran angket terhadap sejumlah orang sebagai responden yang merupakan sampel pilihan kami dari anggota sanggar tari, kemudian pelaksanaan analisa agar dapat ditarik kesimpulan. Urutan analisi yang kami lakukan adalah sebagai berikut : 
1. Mengumpulkan data mengenai populasi yang akan dijadikan bahan acuan pada penelitian ini.

2. Memilih alat pengukuran yang tepat untuk digunakan sebagai sarana perolehan data yang dibutuhkan berdasarkan populasi yang akan jadi focus penelitian. Alat yang dimaksud adalah susunan daftar pertanyaan atau angket.

3. Selanjutnya melakukan penyebaran kuesioner ke populasi yang akan diisi oleh sampel dalam hal ini merupakan anggota sanggar tari yang memenuhi kriteria yang telah ditetapkan.

\section{HASIL DAN PEMBAHASAN}

\section{Analisis Koefisien Determinasi}

Setelah mengetahui bahwa antara kelompok referensi dan budaya terhadap keputusan menjadi anggota sanggar tari terdapat hubungan. Kemudian di pertegas dengan memastikan bahwa antara ketiga variabel tersebut memiliki pengaruh, maka dihitung derajat pengaruh antara faktor kelompok referensi dan budaya terhadap keputusan menjadi anggota sanggar tari dengan menggunakan uji koefisien determinasi sebagai berikut :

Tabel 2 Model Summary

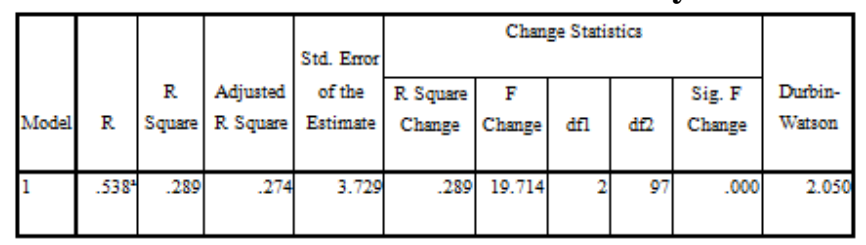

Sumber : Pengolahan Data, 2020

Kemudian, angka R Square adalah 0,289. Hal ini berarti sekitar 28,9\% keputusan menjadi anggota sanggar tari dapat dijelaskan oleh variabel kelompok referensi dan budaya. Sedangkan sisanya $71,1 \%$ dijelaskan oleh sebab-sebab yang lain. Standar error of the Estimate adalah 3.729.

\section{Tabel 3 ANOVA}

ANOVA $^{b}$

\begin{tabular}{|c|c|c|c|c|c|}
\hline Model & Sum of Squares & $\mathrm{df}$ & Mean Square & $\mathrm{F}$ & Sig. \\
\hline $1 \quad$ Regression & 548.345 & 2 & 274.172 & 19.714 & $.000^{\mathrm{a}}$ \\
\hline Residual & 1349.045 & 97 & 13.908 & & \\
\hline Total & 1897.390 & 99 & & & \\
\hline
\end{tabular}

a. Predictors: (Constant), Budaya (X2), Kelompok Referensi (X1)

b. Dependent Variable: Keputusan Menjadi Anggota Sanggar Tari (Y)

Sumber : Pengolahan Data, 2020

Dari uji anova atau F test, didapat F hitung adalah sebesar 19,714 dengan tingkat signifikan menunjukkan nilai 0,000 yang artinya lebih kecil dari $5 \%(0,000<0,05)$, maka sebagaimana dasar pengambilan keputusan dalam uji $\mathrm{F}$, dapat disimpulkan bahsa Kelompok Referensi (X1) dan Budaya (X2) secara bersama-sama (Simultan) Berpengaruh terhadap Keputusan Menjadi Anggota Sanggar Tari (Y).

\section{Tabel 4 Coefficients}

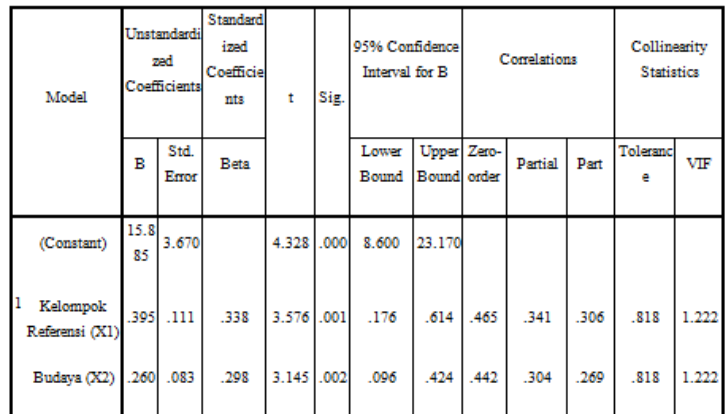

Sumber : Pengolahan Data, 2020

Konstanta sebesar 15.885 menyatakan bahwa jika tidak ada pengaruh kelompok referensi dan budaya maka keputusan menjadi anggota sanggar tari adalah 15.885. Koefisien regresi pengaruh kelompok referensi adalah sebesar 0.395 menyatakan bahwa setiap penambahan pengaruh kelompok referensi akan meningkatkan keputusan menjadi anggota sanggar tari sebesar 0.395 . Koefisien regresi pengaruh budaya adalah sebesar 0.260 menyatakan bahwa setiap penambahan pengaruh budaya akan meningkatkan keputusan menjadi anggota sanggar tari sebesar 0.260 .

\section{Hipotesis 1}

H_(0) : $\boldsymbol{\mu}=\mathbf{0}$ Variabel kelompok referensi tidak mempunyai hubungan dengan Variabel Budaya.

H_(a) : $\boldsymbol{\mu} \neq \mathbf{0}$ Variabel kelompok referensi mempunyai hubungan dengan Variabel Budaya.

\section{Correlation}

Hubungan antara kelompok referensi terhadap variabel budaya adalah 0,426 yang memiliki arti korelasinya sedang. Tingkat signifikannya yaitu 0,000 yang berarti lebih kecil dari 0,005 , ini membuktikan bahwa ada hubungan yang signifikan antara kelompokk referensi terhadap budaya.

Artinya, pada Hipotesis 1 tolak H0 dimana variabel kelompok referensi mempunyai hubungan dengan variabel budaya.

\section{Hipotesis 2}

H_(0) : $\boldsymbol{\mu}=\mathbf{0}$ Variabel kelompok referensi dan variabel budaya tidak mempunyai pengaruh secara parsial pada keputusan menjadi anggota sanggar tari.

H_(a) : $\boldsymbol{\mu \neq 0}$ Variabel kelompok referensi dan 
variabel budaya mempunyai pengaruh secara parsial pada keputusan menjadi anggota sanggar tari.

\section{Statistik T tabel}

Uji signifikan pengaruh kelompok referensi dan budaya terhadap keputusan menjadi anggota sanggar tari dapat dihitung dengan rumus :

T tabel signifikansi 5\%,

(Y) $\mathrm{T}$ hitung $=4,328$

(X1) T hitung $=3,576$

(X2) T hitung $=3,145$

$\mathrm{N}=100$

$\mathrm{Dk} \quad=3$

Df $\quad=100-3=97$

Nilai $\mathrm{t}=1,66071$

Harga $\mathrm{T}$ hitung selanjutnya dibandingkan harga T tabel. Untuk kesalahan 5\% uji dua pihak dan $\mathrm{df}=\mathrm{n}-3=97$ adalah 1,66071. Oleh karena statistik hitung > dari t tabel $(4,328>1,66071)$ maka Ho di tolak. Angka kolom sinifikan adalah 0,000 atau probabilitas jauh dibawah 0.05.

Maka pada Hipotesis 2, Ho ditolak artinya bahwa kelompok Referensi dan Budaya secara parsial memiliki pengaruh yang signifikan terhadap Keputusan menjadi anggota sanggar tari.

\section{Hipotesis 3}

H_(0) : $\boldsymbol{\mu}=\mathbf{0}$ Variabel kelompok referensi dan budaya secara bersama-sama (simultan) tidak mempunyai pengaruh pada keputusan menjadi anggota sanggar tari.

H_(a) : $\boldsymbol{\mu} \neq \mathbf{0}$ Variabel kelompok referensi dan budaya secara bersama-sama (simultan) mempunyai pengaruh pada keputusan menjadi anggota sanggar tari.

\section{KESIMPULAN}

Berdasarkan hasil penelitian yang telah dilakukan menggunakan analisis deskriptif dan verifikatif maka berdasarkan penelitian tersebut dapat diambil kesimpulan sebagai berikut :

1. Gambaran variabel kelompok referensi dapat diukur melalui dimensi normatif, ekspresi nilai, dan informatif. Dimensi yang memperoleh rata-rata skor tertinggi adalah ekspresi nilai dengan persentase sebesar 51,82\% sedangkan dimensi yang memperoleh rata-rata skor terendah adalah normatif dengan persentase sebesar 7,38\%.

2. Gambaran variabel budaya dapat diukur melalui dimensi kepercayaan/keyakinan, pandangan, dan kebiasaan. Dimensi yang memperoleh rata-rata skor tertinggi adalah pandangan dengan persentase sebesar $59.50 \%$ sedangkan dimensi yang memperoleh rata-rata skor terendah adalah kepercayaan/keyakinan dengan persentase sebesar $11.04 \%$.

3. Gambaran variabel keputusan menjadi anggota sanggar tari dapat diukur melalui dimensi motivasi, persepsi, dan kepribadian. Dimensi yang memperoleh rata-rata skor tertinggi adalah kepribadian dengan persentase sebesar 25,57\% sedangkan dimensi yang memperoleh ratarata skor terendah adalah persepsi dengan persentase sebesar $4,88 \%$.

4. Terdapat pengaruh positif hubungan antara variabel kelompok referensi dan budaya. Hubungan antara kelompok referensi terhadap variabel budaya adalah 0,426 yang memiliki arti korelasinya sedang. Tingkat signifikannya yaitu 0,000 yang berarti lebih kecil dari 0,005, ini membuktikan bahwa ada hubungan yang signifikan antara kelompokk referensi terhadap budaya.

5. Harga $T$ hitung selanjutnya dibandingkan harga T tabel. Untuk kesalahan 5\% uji dua pihak dan $d f=n-3=97$ adalah 1,66071. Oleh karena statistik hitung > dari t tabel $(4,328>1,66071)$ maka Ho di tolak. Angka kolom sinifikan adalah 0,000 atau probabilitas jauh dibawah 0.05. Maka artinya bahwa kelompok Referensi dan Budaya secara parsial memiliki pengaruh yang signifikan terhadap Keputusan menjadi anggota sanggar tari.

6. Dari uji anova atau F test, didapat F hitung adalah sebesar 19,714 dengan tingkat signifikan menunjukkan nilai 0,000 yang artinya lebih kecil dari 5\% $(0,000<0,05)$, maka sebagaimana dasar pengambilan keputusan dalam uji F, dapat disimpulkan bahwa Kelompok Referensi (X1) dan Budaya (X2) secara bersama-sama (Simultan) berpengaruh terhadap Keputusan Menjadi Anggota Sanggar Tari (Y).

\section{REFERENSI}

Basu Swastha, H. H. (2011). Manajemen Pemasaran-Analisis Perilaku. Yogyakarta: BPFE.

Dr. Didin Fatihudin, S. M. (2018). Manajemen Jasa (Strategi Mengukur Kepuasan dan Loyalitas Pelanggan).

Hawkins. (2012). Consumer Behaviour. The McGraw.

J.Moleong. (2014). Metode Penelitian Kualitatif. 
Bandung: PT. Remaja Rosdakarya .

Kotler, A. (2012). Manajemen Pemasaran Edisi 12. Jakarta: Erlangga.

Kotler, H. P. (2012). Principles of Marketing Global 14th Edition. New Jersey: Prentice.

Kotler, P. K. (2016). Marketing Management, 15th Edition. New Jersey: Pearson Pretice Hall, Inc.

Peter, O. (2013). Perilaku Konsumen dan Strategi Pemasaran. Jakarta: Salemba Empat.

Schiffman, K. (2013). Consumer Behaviour. New Jersey: Prentice Hall.

Silaen, S. (2018). Penelitian Sosial untuk Penulisan Skripsi dan Tesis. Bogor: In Media.

Sugiyono. (2015). Metode Penelitian Kuantitatif, Kualitatif, dan $R \& D$. Bandung: Alfabeta.

Sugiyono. (2016). Metode Penelitian Kuantitatif, Kualitatif, dan $R \& D$. Bandung: PT Alfabeta.

Sugiyono. (2017). Metode Penelitian Kuantitatif, Kualitatif, dan $R \& D$. Bandung: CV Alfabeta.

Sumarwan, U. (2011). Perilaku Konsumen: Teori dan Penerapannya dalam Pemasaran. Bogor: Ghalia Indonesia. 